and can only change by a displacement of the wall itself. Other orifices admit to the circle the light of a lamp and enable the divisions to be read. These are drawn at every five minutes of the circle, which then bears 4,320 equidistant marks; each microscope is provided with a micrometer which enables the tenths of a second of arc to be observed.

If now, by observations of the pole star at its upper and lower transits, the observer determines in the same way the direction of the telescope looking to the pole, the angle comprised between that direction and that of the telescope directed to the star will give the polar distance of the star. If by means of a mercury bath he determines the direction of the telescope when its optical axis is vertical, he will ascertain in the same way the distance of the star from the zenith.

These observations may be made in the two positions which the telescope takes before and after being turned round. This is why it carries two cast-iron circles roughly graduated and two brass circles finely graduated on silver, which on the reversal of the instrument are substituted for each other before the pointer-telescope and the fixed microscopes. The arrangement of these circles insures a perfect symmetry to the instrument, an essential condition if we wish to prevent irregular deformations.

But these operations will only give the co-ordinates of the star if they are made with an instrument set in the meridian of the place. It is necessary then that the telescope should turn round a horizontal axis, that it should be perpendicular to that axis, and that the plane which it describes in turning should pass through the pole of the earth. A level, which the illustration represents resting by two forks upon the pivots of the telescope, but which during the observations is raised by means of a crane fixed to the ceiling, serves to measure and correct the inclination of the axis of rotation. By turning it upon a long support the perpendicularity of the optical axis on the axis of the pivots can be assured. Two supports are to be constructed, one on the north, the other on the south ; the latter only has been made. Finally the astronomical observation of the pole star indicate if the last of the three conditions is fulfilled.

A word on the illumination of the system of cross wires visible in the eye-piece. During the day they stand out on the clear background of the sky; at night the same effect is obtained by means of a ray of light proceeding from a gas-lamp fixed on the west pillar, the rays of which are sent towards the eye-piece by a small prism fixed in the middle of the telescope. A screen with a variable opening, or cat's-eye, permits the intensity of the light to be proportioned to the brightness of the star observed. Finally, for very weak stars a very simple mechanical arrangement suppresses all light in the field, and brings it to bear on the wires, which appear as luminous lines on a background absolutely dark.

The long illness of M. Leverrier did not permit him to push on, so actively as he would have wished, the preliminary investigations of this beautiful instrument, among which we must mention one, long and difficult - the divisions of the two circles. It will, without doubt, be facilitated by this circumstance, that, traced by means of the dividing machine constructed by $M$. Eichens, the lines present a regularity and a finish altogether favourable to precision.

The astronomers of the observatory will hold it a point of honour to take advantage as soon as possible of the magnificent apparatus which they owe to the generosity of M. Bischoffsheim.

\section{FETICHISM IN ANIMALS}

M R. HERBERT SPENCER, in his recently pub1 lished work on the "Principles of Sociology," treats of the above subject. He says: "I believe M. Comte expressed the opinion that fetichistic conceptions are formed by the higher animals. Holding, as I have given reasons for doing, that fetichism is not original but derived, I cannot, of course, coincide in this view. Nevertheless, I think the behaviour of intelligent animals elucidates the genesis of it. I have myself witnessed, in dogs, two illustrative cases." One of these cases consisted in a large dog, which, while playing with a stick, accidentally thrust one end of it against his palate, when, "giving a selp, he dropped the stick, rushed to a distance from it, and betrayed a consternation which was particularly laughable in so ferocious-looking a creature. Only after cautious approaches and much hesitation was he induced again to lay hold of the stick. This behaviour showed very clearly the fact that he stick, while displaying none but the properties he was familiar with, was not regarded by him as an active agent, but that when it suddenly inflicted a pain in a way never before experienced from an inanimate object, he was led for the moment to class it with animate objects, and to regard it as capable of again doing him injury. Similarly in the mind of the primitive man, knowing scarcely more of natural causation than a dog, the anomalous behaviour of an object previously classed as inanimate, suggests animation. The idea of voluntary action is made nascent; and there arises a tendency to regard the object with alarm, lest it should act in some other unexpected and perhaps mischievous way. The vague notion of animation thus aroused will obviously become a more definite notion, as fast as development of the ghost-theory furnishes a specific agency to which the anomalous behaviour can be ascribed."

The other case observed by Mr. Spencer was that of an inteiligent retriever. Peing by her duties as a retriever led to associate the fetching of game with the pleasure of the person to whom she brought it, this had become in her mind an act of propitiation; and so, "after wagging her tail and grinning, she would perform this act of propitiation as nearly as practicable in the absence of a dead bird. Seeking about, she would pick up a deadleaf or other small object, and would bring it with renewed manifestations of friendliness. Some kindred state of mind it is which, I believe, prompts the savage to certain fetichistic observances of an ancmalous kind."

These observations remind me of several experiments which I made some years ago on this subject, and which are perhaps worth publishing. I was led to make the experiments by reading the instance given in the "Descent of Man," of the large dog which Mr. Darwin observed to bark at a parasol as it was moved along a lawn by the wind-so presenting the appearance of animation. The dog on which I experimented was a Skye terrier-a remarkably intelligent animal, whose psychological faculties have already formed the subject of several communications to this and other periodicals. ${ }^{i}$ As all my experiments yielded the same results I will only mention one. The terrier in question, like many other dogs, used to play with dry bones by tossing them in the air, throwing them to a distance, and generally giving them the appearance of animation, in order to give himself the ideal pleasure of worrying them. On one occasion, therefore, I tied a long and fine thread to a dry bone and gave him the latter to play with. After he had tossed it about for a short time I took an opportunity when it had fallen at a distance from him and while he was following it up, of gently drawing it away from him by means of the long and invisible thread. Instantly his whole demeanour changed. The bone which he had previously pretended to be alive now began to look as if it really were alive, and his astonishment knew no bounds. He first approached it with nervous caution, as Mr. Spencer describes, but as the slow receding motion continued, and

I See especially an article on "Conscience in Animals," in Quarterly Foumal of Science for April, 1876 . 
he became quite certain that the movement could not be accounted for by any residuum of the force which he had himself communicated, his astonishment developed into dread, and he ran to conceal himself under some articles of furniture, there to behold at a distance the "uncanny" spectacle of a dry bone coming to life.

Now in this, and in all my other experiments, I have no doubt that the behaviour of the terrier arose from his sense of the mysterious, for he was of a highly pugnacious disposition, and never hesitated to fight an animal of any size or ferocity ; but apparent symptoms of spontaneity in an inanimate object which he knew so well, gave rise to feelinos of awe and horror which quite enervated him. And that there was nothing fetichistic in these feelings may be safely concluded if we reflect, with Mr. Spencer, that the dog's knowledge of causation, for all immediate purposes, being quite as correct and no less stereotyped than is that of "primitive man," when an object of a class which he knew from uniform past experience to be inanimate suddenly began to move, he must have felt the same oppressive and alarming sense of the mysterious which uncultured persons feel under similar circumstances. But further, in the case of this terrier we are not left with a prior $i$ inferences alone to settle this point, for another experiment proved that the sense of the mysterious was in this animal sufficiently strong of itself to account for his behaviour. Taking him into a carpeted room I blew a soap-bubble, and by means of a fitful draught made it intermittently glide along the floor. He became at once intensely interested, but seemed unable to decide whether or not the filmy object was alive. At first he was very cautious and followed it only at a distance, but as I encouraged him to examine the bubble more closely, he approached it with ears erect and tail down, evidently with much misgiving; and the moment it happened to move he again retreated. After a time, however, during which I always kept at least one bubble on the carpet, be began to gain more courage, and the scientific spirit overcoming his sense of the mysterious, he eventually became bold enough slowly to approach one of the bubbles and nervously to touch it with his paw. The bubble, of course, immediately vanished; and I certainly never saw astonishment more strongly depicted. On then blowing another bubble, I could not persuade him to approach it for a good while; but at last he came and carefully extended his paw as before with the same result. But after this second trial nothing would induce him again to approach a bubble, and on pressing him he ran out of the room, which no coaxing would persuade him to re-enter.

One other example will suffice to show how strongly developed was the sense of the mysterious in this animal. When alone with him in a room I once purposely tried the effect on him of making a series of horrible grimaces. At first he thought I was only making fun; but as I persistently disregarded his caresses and whining while I continued unnaturally to distort my features, he became alarmed and slunk away under some furniture, shivering like a frightened child. He remained in this condition till some other member of the family happened to enter the room, when he emerged from his hiding-place in great joy at seeing me again in my right mind. In this experiment, of course, I refrained from making any sounds or gesticulations, lest he might think I was angry. His actions, therefore, can only be explained by his horrified surprise at my apparently irrational behaviour-i.e., by the violation of his ideas of uniformity in matters psychological. It must be added, however, that I have tried the same experiment on less intelligent and less sensitive terriers with no other effect than causing them to bark at me.

I will only add that I believe the sense of the mysterious to be the cause of the dread which many animals show of thunder. I am led to think this, because I once had a setter which never heard thunder till he was eighteen months old, and on then first hearing it I thought he was about to die of fright, as I have seen other animals do under various circumstances. And so strong was the impression which his extreme terror left behind, that whenever afterwards he heard the boom of distant artillery practice, mistaking it for thunder, he became a pitiable object to look at, and, if out shooting, would immediately bolt home-or, if at a great distance from home, would endeavour to bury himself. After having heard real thunder on two or three subsequent occasions, his dread of the distant cannons became greater than ever; so that eventually, though he keenly enjoyed sport, nothing would induce him to leave his kennel, lest the practice might begin when he was at a distance from home. But the keeper, who had a large experience in the training of dogs, assured me that if I allowed this one to be taken to the battery, in order that he might learn the true cause of the thunder-like noise, he would again become serviceable in the field. The animal, however, died before the experiment was made. GEORGE J. ROMANES

\section{RUHMKORFF}

WE regret to record the sudden death on December 20, at Paris, of Henry Daniel Ruhmkorff, whose name is so closely connected with the history of magnetoelectricity. He was born in Hanover, Germany, in 1803, and but little is known of his early life. In I819 he wandered to Paris, and obtained a position as porter in the laboratory of Prof. Charles Chevalier, at that time one of the leading French physicists. Here he displayed a remarkable fondness for electrical apparatus, as well as ingenuity in its arrangement, and was enabled shortly after to start a modest manufactory of physical apparatus. Through the efforts of Chevalier and the excellence of the work performed, the business was rapidly extended. In I 844 Ruhmkorff brought out his first invention, a convenient thermo-electric battery. Soon after he turned his attention to magneto-electricity, especially the production of the induced currents, discovered by Faraday in I832. A long series of experiments resulted in the appearance, in $185 \mathrm{I}$, of the famous "Ruhmkorff coil," with its later modifications, the most important piece of apparatus in this branch of physics. With this powerful adjunct the electrician was enabled to obtain sparks 18 inches in length, pierce thick plates of glass, and carry out a vast variety of experiments. The invention was rewarded by a decoration and medal at the Exhibition of 1855 , while in 1858 it received the first prize of 50,000 francs at the French Exhibition of Electrical Apparatus. Since then the manufacture of the coils and of electrical machines in general has assumed enormous dimensions, and the leading physicists of Europe are well acquainted with the dingy little bureau in the Rue Champollion, near the University. Personally M. Ruhmkorff was of a quiet, dignified appearance, and despite the disadvantages of his early life, he enjoyed the friendship of the leading Parisian savants, and was an honoured member of the French Physical Society. M. Jamin delivered an address over the grave, in which he stated that Ruhmkorff died almost a poor man, because he had spent all his earnings on behalf of science and in works of benevolence.

\section{LIQUEFACTION OF OXYGEN}

THE number of the permanent gases is rapidly diminishing. We have had occasion recently to refer to M. Cailletet's successful attempts to compress nitric oxide, $\mathrm{N}_{2} \mathrm{O}_{2}$, methyl hydride, $\mathrm{CH}_{4}$, and acetylene, $\mathrm{C}_{2} \mathrm{H}_{2}$, to the liquid form. The list of non-compressible gases was thus reduced to three, viz., hydrogen, nitrogen, and oxygen. Within the past week M. Raoul Pictet has succeeded in obtaining the last-mentioned gas in the liquid state, an event which is certainly one of the most 